\title{
A (de)formação da formação inicial dos professores na perspectiva da escola inclusiva
}

\author{
Vanderlei Balbino Costa \\ Universidade Federal de Jataí (UFJ), Jataí - Goiás - Brasil. Docente do \\ Programa de Pós-Graduação em Educação (PPGE/UFJ). Pós Doutorando \\ em Educação no Programa de Pós-Graduação em Educação \\ (PPGE/UERJ). Bolsista PNPD/CAPES. \\ ORCID: https://orcid.org/0000-0002-1330-747X. \\ E-mail: vanderleibalbino@gmail.com
}

\section{Leonor Paniago Rocha}

Universidade Federal de Jataí (UFJ), Jataí - Goiás - Brasil. Pós Doutora em Educação. Bolsista PNPD/CAPES.

ORCID: https://orcid.org/0000-0003-1076-703X

E-mail: leonorpaniago.ufg@hotmail.com

\section{Adrielle Martins de Lima}

Universidade Federal de Jataí (UFJ), Jataí - Goiás - Brasil. Mestranda do Programa de Pós-Graduação em Educação (PPGE/UFJ).

ORCID: https://orcid.org/0000-0003-4050-9189

E-mail: adriellemartins56@gmail.com 


\section{Resumo}

A formação de professores sempre foi marcada por dificuldades, e os discursos sobre ela são os de que não há investimento nas licenciaturas. Nesse sentido, este texto relata uma pesquisa que objetiva fazer uma reflexão sobre a formação inicial e possui como questão de investigação: quais limites e desafios são encontrados, pelos professores, na formação inicial e continuada. Objetiva também conhecer como vem ocorrendo a formação inicial dos professores na perspectiva da escola, intitulada atualmente, como inclusiva; analisar, até que ponto, os limites e desafios da inclusão têm interferido no processo de inclusão dos alunos com deficiência; discutir as causas, nas quais a formação inicial, nas licenciaturas, não têm formado os professores nas escolas. Os resultados desta, mostraram insuficiência na formação dos professores para atuar na escola inclusiva. Assim, consideramos que a formação inicial passa por processo de (de)formação, considerando que as licenciaturas não contam com disciplinas de educação especial.

PALAVRAS-CHAVE: Formação de professores. Deformação da formação inicial. Escola inclusiva.

\section{Abstract}

Teacher training has always been marked by difficulties, and the discourses about it are that there is no investment in licentiate degrees. In this sense, this text reports a research that aims to reflect on initial formation and has as a research question: what limits and challenges are found by teachers in initial and continuing education. It also aims to get to know how the initial formation of teachers has been taking place from the perspective of the school, currently entitled as inclusive; to analyze, to what extent, the limits and challenges of inclusion have interfered in the inclusion process of students with disabilities; discuss the causes, in which initial training, in licentiate degree, have not trained teachers in schools. The results of this, showed insufficient training of teachers to work in the inclusive school. Thus, we consider that initial training goes through the process of (de)formation, considering that the licentiate degrees do not have special education disciplines.

KEYWORDS: Formation of teachers. Deformation of the initial formation. Inclusive school. 


\title{
Introdução
}

A adversidade desperta em nós capacidades que, em circunstâncias favoráveis, teriam ficado adormecidas" (Horácio).

Atualmente, a escola inclusiva tem sido instrumento de debate nos mais diversos níveis de ensino, exatamente porque pressupõe mudanças legais, estruturais e didático- pedagógicas em todos os segmentos.

Frente a essa a premissa, Thomas (2006, p. 1) afirma que:

\begin{abstract}
A educação inclusiva tem sido tema de reflexão e ansiedade para educadores e educadoras em todos os níveis de ensino, pois pressupõe mudanças textuais/legais, simbólicas (curriculares, avaliativas etc), de representações sobre os sujeitos a serem incluídos e das identidades de todos os envolvidos no processo.
\end{abstract}

A inclusão no ensino comum, decretada pelas instâncias administrativas e proposta em um discurso que se apoia na inclusão escolar independentemente se a escola tem ou não condições para tanto, nos faz pensar que, atualmente, esse espaço tornou-se um lugar no qual, parte dos docentes e demais segmentos, não se encontram preparados para receber os estudantes com deficiência.

Para realizar a discussão a respeito do que estamos chamando de (de)Formação inicial nas licenciaturas, apoiamos nos escritos de Thoma (2006, p. 1), que assinala que "a exclusão de alguns e a inclusão de outros sempre foi uma marca da instituição escolar moderna, mas somente nos últimos anos isso deixa de ser naturalizado, passando a ser problematizado". Essa condição exige que sejam tomadas as providências, sob pena de entrarmos em um processo que muito bem poderíamos caracterizar como "inclusão excludente", em que alunos e alunas entram pela porta da frente (via vestibular ou outros processos seletivos), mas encontram uma instituição que pouco ou nada tem a oferecer. Nesse sentido, somos "hospedeiros", cuja casa não se encontra em condições de 
receber culturas, identidades e alteridades distintas do modelo de normalidade constituído social, cultural, linguística e historicamente.

A nosso ver, isso incorre em problemas graves na escola, considerando que o discurso é do despreparo dos professores, surgindo daí uma grande reflexão: até quando os alunos com deficiência irão esperar a escola se adaptar e os professores se qualificarem para receber nos espaços educativos esses novos sujeitos sociais?

No que concerne a legislação educacional, em nível nacional, é relevante assinalar que foi somente com a publicação da Lei de Diretrizes e Bases da Educação Nacional (LDBEN) nº. 9.394/96, que se passou a dar, efetivamente, mais enfoque na inclusão escolar dos alunos com deficiência, quando orienta que esses devem ser matriculados preferencialmente no ensino comum.

No cenário internacional, é relevante acentuar que os anos de 1990, borbulharam movimentos em favor da inclusão escolar, (JOMTIEN, 1990); (SALAMANCA, 1994). Quando se refere ao Brasil, é notório assinalar que a década de 1990, caracterizou-se como um período de reformas no que concerne à educação. Assim, essas reformas contemplaram diversos setores da educação, dentre eles, a inclusão escolar.

Cumpre-nos assinalar que essas reformas por sua vez podem ser observadas, por exemplo, na LDBEN nº 9.394/96 que teve pela primeira vez um capítulo específico voltado a educação de pessoas com deficiência.

No mundo moderno, globalizado, sem fronteiras, pensamos que um dos princípios fundamentais da Educação nos sistemas inclusivos é garantir direitos, acesso, sucesso e permanência de todos os alunos com ou sem deficiências no ensino comum.

No contexto da formação docente é necessário assinalar que o "processo" de conscientização, dialogicidade, humanização e libertação, não se dá apenas pelas vias da educação escolar. É por esta razão que a reflexão baseada nos 
preceitos Freireanos parte do princípio de que é impossível a educação sem que educador e educando eduquem-se a si mesmos, rumo ao processo de sua libertação. Assim, torna-se evidente que sem uma educação que busque promover a conscientização, o processo de dialogicidade, de humanização, não será efetivado a conquista da nossa cidadania. Partindo dessa premissa, apoiamo-nos em Fiori (1986, p.3) ao acentuar que "só assim será possível repor os termos dos problemas de uma educação autenticamente libertadora: força capaz de ajudar a desmontar o sistema de dominação, e promessa de um homem novo, dominador do mundo e libertador do homem".

No atual modelo de educação que temos, pensamos que a inclusão e a escolarização se legitimam a partir das necessidades de que todos, sem distinção, não devem ser excluídos. Frente ao exposto, Mantoan (2003, p. 53) considera que:

\begin{abstract}
A escola, para muitos alunos, é o único espaço de acesso aos conhecimentos. É o lugar que vai proporcionar-lhes condições de se desenvolverem e de se tornarem cidadãos, alguém com uma identidade sociocultural que lhes conferirá oportunidades de ser e de viver dignamente.
\end{abstract}

No contexto da formação, ou da (de)Formação inicial nas licenciaturas, quando a perspectiva da escola é incluir todos os alunos, independente se esses são ou estão em situação de deficiência, é de fundamental importância ressaltar que a noção de inclusão é objeto de uma ampla proposta, a qual não se configura em um mero mecanismo. Ao contrário, requer dos professores uma nova postura frente a essa situação, como por exemplo, tomada de decisão, trabalho pedagógico e uma concepção política capaz de fazer com que possam construir no espaço escolar uma educação libertadora, humana e humanizante. Nessa perspectiva Laplane (2006, p. 75) comenta que: 


\begin{abstract}
A discussão interna sobre a função social da escola, a construção de um projeto pedagógico que privilegie práticas heterogêneas e $\mathrm{o}$ protagonismo dos professores são vistos como chaves para a inclusão. Os sistemas escolares são instados a assegurar a matrícula de todos os alunos e a organizar-se para atendê-los. Devem oferecer os recursos pedagógicos necessários e capacitar profissionais para atender às demandas dos alunos.
\end{abstract}

Logo, nossa convivência nos cursos de licenciaturas, formando professores para atuarem nas escolas comuns, tem como maior inquietação/indagação nessa reflexão: quais são os maiores limites e desafios encontrados pelos professores em seu processo de formação inicial e continuada, cuja intensão é incluir os alunos com deficiência na escola comum?

Assim, nesta pesquisa, nossos objetivos foram: conhecer como vem ocorrendo a formação inicial dos professores na perspectiva da escola inclusiva; analisar até que ponto os limites e desafios da inclusão têm interferido no processo de inclusão dos alunos com deficiência no ensino comum; discutir as causas pedagógicas pelas quais a formação inicial nas licenciaturas não vem dando conta de formar os novos professores para atuar nas escolas comuns, quando o alvo é o processo de inclusão escolar dos alunos com deficiência.

\title{
Método
}

Nossa opção nesta investigação foi pela abordagem qualitativa. Ludke e André, (1986, p. 11), assinalam que: "a pesquisa qualitativa tem o ambiente natural como sua fonte direta de dados e o pesquisador como seu principal instrumento". Desse modo, ancorados nos pressupostos teóricos que discutem a formação inicial e continuada de professores que vão atuar nas escolas, lançamos mão de referenciais bibliográficos que deram suportes para discutir limites e desafios encontrados pelos professores em seu processo de formação. 
Por se tratar de uma investigação nas escolas, acerca da formação dos professores, lançamos mão de bibliografias como Severino (2007, p.123), que acentua que: "nas investigações bibliográficas o pesquisador parte das pesquisas já existentes para fundamentar seu trabalho".

Se levarmos em conta que nossa pesquisa utilizou-se de decretos, legislações, resoluções e documentos oficiais, apoiamos também em Piana, (2009, p. 122), ao assinalar que: "a pesquisa documental apresenta algumas vantagens por ser fonte rica e estável de dados': não implica altos custos, não exige contato com os sujeitos da pesquisa e possibilita uma leitura aprofundada das fontes".

Assim, intencionamos investigar nesta pesquisa quais são as maiores dificuldades que os novos docentes vem enfrentando para ministrar aulas para alunos com deficiência, transtornos globais do desenvolvimento e altas habilidades/superdotação.

\section{Fundamentação Teórica}

Ao dialogar com a literatura que aborda a inclusão de todos no contexto da escola, principalmente quando nos referimos à formação docente nos diferentes níveis de ensino, é possível ressaltar que hoje se registra na educação escolar alguns limites que, na perspectiva de uma escola inclusiva, precisam ser eliminados.

Discursos sobre a necessidade de investir na formação inicial nas licenciaturas, podem ser evidenciados nos escritos Santos; Santos filho; Santos; Araújo (2006, p. 8), que afirmam que "se não existe uma cultura inclusiva na sociedade como um todo e nas instituições de ensino, fatalmente se estará comprometendo a formação de professores, não apenas no curso de pedagogia, mas em todas as demais licenciaturas $[. .]$.$" . Associado a isso, vivemos um$ 
momento histórico em que a falta de recursos compromete a capacitação dos membros da equipe da escola em lidar com essa realidade.

Frente a essa problemática, insistimos, sem formação inicial de qualidade, na qual, defendemos a inserção de disciplinas de educação especial, nas grades curriculares dos cursos, nossas licenciaturas seguramente estarão (de)formada, fragmentada, enfim, desconectada da realidade, na qual, a inclusão escolar dos alunos com deficiência estará comprometida.

À luz da literatura que enfoca a produção científica na educação especial, identificamos em nossa pesquisa diversos trabalhos que apontam para os limites, no que concerne as fragilidades dos professores para atuar na escola comum, quando nessas registra-se a presença de alunos com deficiência.

Os limites da formação inicial dos professores podem ser verificados em Carneiro (1999) que identificou em sua pesquisa com professores do ensino fundamental que é unânime o discurso destes sobre a necessidade de formação. Nessa mesma direção, Magalhães (1999), ao ouvir a opinião de professores e diretores sobre a inclusão escolar de alunos com deficiência na escola comum, destaca a importância da formação inicial para a execução de uma escola inclusiva.

Ao se referir à formação inicial na perspectiva da escola inclusiva, é notório assinalar que os limites dessa formação se verificam a partir do momento que não há, pelos gestores públicos, projetos educacionais que possam atender a real demanda da sociedade. Esses limites são apontados por Mazzotta (2005, p. 128) ao acentuar: "compartilho do entendimento de que, uma política se define por um conjunto coerente de princípios, propostas, instrumentos e recursos de ação pública".

Ao direcionar nosso olhar para a literatura que aponta alguns limites à formação inicial nas licenciaturas, identificamos nos escritos de Chacon (2004) que há algumas dificuldades para que outras áreas, além da educação e 
psicologia, possam contemplar em suas grades, disciplinas em educação especial, contribuindo para a formação de recursos humanos na docência e para outros profissionais que estão ou vão atuar nas escolas, nas quais registra-se matrícula de alunos com deficiência, transtornos globais do desenvolvimento e altas habilidades/superdotação.

Um dos dilemas da formação para atuar na educação especial está na nossa própria formação profissional, pois além das poucas disciplinas que se oferece nas licenciaturas, essas são, por sua vez, fragmentadas, não permitindo uma formação inicial consistente. Frente a essa assertiva, Chacon (2004, p. 333334) observa:

Nossas limitações nos impedem, muitas vezes, de atender a algumas demandas sociais e mesmo institucionais, o que nos leva a necessitar do outro para complementar os cursos que ministramos com conteúdo que, algumas vezes, não dominamos por completo. Há que se modificar o trabalho de cátedra realizado, ainda, isoladamente.

\section{Discussão e Construção dos Resultados}

No que se refere aos limites da formação dos professores para atuar no ensino comum com alunos com deficiência, Ferreira (1998, p.34) afirma que:

O tema das necessidades especiais, ou mesmo da diversidade, é ainda pouco presente nos cursos de formação de professores e outros profissionais, mesmo com recomendações e indicações legais para que se supere essa lacuna. De outra parte, parece difícil capacitar os professores das classes comuns para integrar alunos que ainda não estão presentes na escola em que trabalham.

De igual modo, identificamos no decorrer desta pesquisa que, os professores, em sua maioria, terminam os cursos de licenciaturas, vão para as escolas, se deparam com alunos com deficiência em suas salas de aula e, são 
obrigados a enfrentar uma realidade, para qual não foram preparados no decorrer de sua formação inicial.

Ao longo dessa convivência, seja como aluno, seja ainda como professor/formador, temos percebido que um dos limites na formação inicial é a falta de disciplinas de educação especial nas licenciaturas, considerando que os novos professores, uma vez formados, vão atuar nas escolas comuns e, por conseguinte, se deparar com alunos com deficiências diversas. Essas lacunas podem ser vivenciadas na portaria ministerial no 1793, publicada em 1994, que, embora proponham a introdução de disciplinas e educação especial, em todos os cursos de formação, isso se dá apenas em nível de recomendação.

Ao nosso ver, isso incorre em um grave problema, uma vez que recomendar apenas não significa obrigatoriedade, e, não sendo obrigatório, as universidades, os sistemas públicos e gestores não se sentem obrigados a ofertarem essas disciplinas em suas grades curriculares.

Não é recorrente na literatura que discute a formação inicial nas licenciaturas, críticas à decisão do Conselho Nacional de Educação (CNE), em 2006, quando retirou dos cursos de pedagogia as habilitações em educação especial nas áreas de deficiência intelectual, visual, surdez e física.

Em nossa concepção, essa decisão vai na contramão da inclusão escolar, pois se considerarmos que ao redor do mundo borbulhavam movimentos em prol da inclusão de todas as pessoas com deficiência, no Brasil, este órgão deleta ações políticas que poderiam ampliar as discussões nos cursos de formação inicial em todas as licenciaturas. Em nossa análise, isso incorre em um grave problema, uma vez que em depoimento, coletado nessa pesquisa, os professores afirmam que mesmo com formação já é difícil promover a inclusão dos alunos com deficiência, transtornos globais do desenvolvimento e altas habilidades superdotação. 
Defendemos a tese de que a falta de formação inicial nas licenciaturas se configura em grandes limites aos professores, contribuindo para que na escola haja processos de marginalização dos alunos com deficiência. Percebemos esses limites quando da nossa imersão nas escolas, ao presenciar que esses profissionais não fazem adaptação do currículo às diferentes necessidades educativas especiais, não flexibilizam as avaliações, não preparam recursos didáticos, procedimentos metodológicos e estratégias de ensino diferenciadas aos sujeitos com deficiência matriculados nas escolas comuns em todos os níveis (COSTA, 2018).

Nos processos inclusivos, a avaliação se configura como limitadora da inclusão dos alunos com deficiência, considerando que há impregnado no imaginário docente a falsa ideia de que devemos avaliar os alunos da mesma forma, do mesmo jeito, enfim, fazendo comparações entre todos. Lopes (2010), condena essa arcaica postura, propondo que os alunos com deficiência devem ser avaliados de acordo com seus próprios desempenhos e jamais por critérios comparativos, uma vez que aprendem em tempos e ritmos diferentes. Constatamos nessa investigação, quando da nossa participação nas escolas, que a formação desses profissionais no ensino superior foi descontextualizada da realidade, na qual, encontra-se as escolas que se propõem inclusivas.

No decorrer dessa investigação, vivendo e convivendo no chão da escola, consideramos que um dos grandes limites da literatura que enfatiza a formação inicial são as adaptações curriculares, pouco abordadas nos cursos de formação. Portanto, cumpre-nos acentuar que elas pressupõem a possibilidade de atuar frente as necessidades especiais dos alunos com deficiência, adaptando, quando necessário, atividades, conteúdos, currículo e avaliações.

Assim, somos insistentes em afirmar que, os limites da formação inicial se dão pela ausência de disciplinas de educação especial nas grades curriculares. Dialogando com os professores no decorrer da pesquisa, esses profissionais 
afirmaram que "não foram preparados para ministrar aulas para alunos com deficiência na universidade, quando fizeram sua graduação". Na nossa concepção, a falta de formação esbarra no processo de inclusão dos alunos com deficiência.

Sem formação, para atuar nas escolas, os professores são unanimes em afirmar: "se não formos formados, habilitados na área da educação especial, enfim, se nossos cursos não tiverem disciplinas de inclusão, certamente, vamos continuar fazendo avaliações comparativas, uma vez que não respeitamos e reconhecemos as diferenças nos espaços da escola, ladeada pela diversidade dos nossos alunos".

Identificamos com pesquisa, que uma das maiores dificuldades em propor as adaptações curriculares nos cursos de formação inicial estão na insegurança dos professores, que não receberam formação para desempenhar essa tarefa. Isso se evidencia no discurso de uma de nossas entrevistadas ao mencionar: "durante minha graduação não tive nenhuma disciplina de educação especial, apenas uma de Libras, porém, Libras ensina apenas incluir alunos surdos, e, os outros, como ficam?".

No ensino superior, quando se refere a formação para atuar com as diferenças, essas dificuldades se tornam mais acentuadas. Evidencia-se essa defasagem nos depoimentos dos professores quando se manifestam: "quando o foco são as adaptações do currículo, dos conteúdos, dos procedimentos, dos recursos didáticos e da flexibilização das avaliações, sentimos totalmente perdidos, por que, não fomos preparados para incluir nas escolas esses sujeitos".

Concluímos, a partir dos depoimentos, que essas tarefas não são sempre bem vistas pelos professores, uma vez que não recebem formação para fazer as adequações no currículo. (GONZALES, 2007); (COSTA, 2016). Assim, é notório acentuar que há referenciais que comprovam essa questão. Diante dessa assertiva, Mazzotta (2008. p. 27.) observa que: 
Enquanto modalidade de organização didática e administrativa integrante do sistema escolar brasileiro, a Educação Especial tem se constituído em um continuado desafio para estudantes, pais, professores, administradores, legisladores, pesquisadores e comunidade em geral.

Ao longo dessa pesquisa, convivendo nas escolas com diversos professores, o maior desafio que se apresenta à formação inicial é romper com a ideia de que encastelados nessas escolas, alguns parecem não demonstrar boa receptividade aos sistemas inclusivos de educação, alegando: despreparo, falta de qualificação e habilitação para receber na sala de aula, alunos com deficiência, transtornos globais do desenvolvimento e altas habilidades/superdotação no ensino comum.

A escola atual, desenhada nesse novo milênio, se apresenta como uma instituição aberta às diferenças, considerando que estão matriculados indígenas, quilombolas e pessoas com deficiência, fazendo com que esse espaço se torne hospedeiro de uma diversidade plural constituída pelas diferenças. Por essa razão, a diversidade é entendida como uma constituição histórica, social, cultural e política das diferenças, na qual, registra-se uma multiplicidade de culturas heterogêneas, rica aos processos educativos.

Sabemos que a nossa formação inicial é fragmentada. Sabemos também que ela se encontra (de)formada no mundo neoliberal, carcomida pela globalização que pôs fim às fronteiras. Nesse cenário, um dos maiores desafios dos professores é construir uma proposta de currículo adaptado, capaz de atender as necessidades dos nossos alunos com e sem deficiência. Isso posto, cumpri-nos indagar: o que define as adaptações curriculares? o que os alunos precisam aprender, como e quando aprender, como e de que forma avaliar, por que avaliá-los? 
Refletindo sobre essas questões afirmamos que os grandes desafios que os professores encontram na formação inicial nas licenciaturas é a promoção da igualdade de oportunidade, respeitando as necessidades individuais de cada sujeito. Para tanto, só nos resta investir na formação continuada desses profissionais que já estão ou vão adentrar nas escolas, propiciando melhorias nas condições de trabalho, removendo barreiras pedagógicas que dificultam os processos inclusivos no sistema educacional, da educação infantil ao ensino superior.

Não é utopia a crença de que na formação inicial é possível realizar trabalhos cooperativos envolvendo professores do ensino comum e professores do ensino especial, considerando que a literatura especializada já demonstrou que isso é possível. Em nossas pesquisas acerca da formação inicial nas licenciaturas, não se constitui sonhos acreditar que os professores, (generalistas e especialistas), podem e devem trabalhar de forma colaborativa, ajudando, auxiliando e planejando juntos currículos, conteúdos, procedimentos de ensino, recursos didáticos e avaliações diferenciadas.

Ao se referir o processo de educabilidade dos alunos com deficiência, consideramos ser as famílias uma das mais importantes parceiras, uma vez que convivem com os filhos, conhecem suas necessidades especificas, podendo contribuir de forma includente em seu processo formativo.

\section{Considerações Finais}

Nossas considerações nessas reflexões não são finais, nem ao menos conclusivas, até por que, não cremos no pronto e acabado, no definitivo. Ao contrário, acreditamos sim, na possibilidade de melhorar, ampliar e qualificar cada vez mais nossa formação inicial e continuada. Para isso, a universidade tem pela frente grandes desafios, a saber: 
a) construir currículos adaptados que possibilitem a inclusão de todas as pessoas, independente se essas esteja ou não em situação de deficiência;

b) garantir atendimento educacional especializado as diferentes necessidades educativas especiais;

c) valorizar as diferenças na e para a diversidade, eliminando a homogeneidade;

d) avaliar para emancipar e não para quantificar- medir saberes previamente determinado pelo sistema que ainda é celetista, excludente e conservador.

Hoje, frente às demandas que o mundo globalizado nos impõe, por meio das ações políticas neoliberais, seguramente, não temos dúvidas em afirmar que é função precípua da escola adaptar o currículo em todos os níveis, de modo que os espaços educativos possam se tornar acessíveis a todas as pessoas, eliminando barreiras físicas, comunicacionais, sistêmicas, pedagógicas e atitudinais, ainda presentes nos processos inclusivos.

$\mathrm{Na}$ conjuntura atual que se desenha, constitui como grandes desafios impregnar no imaginário dos professores que a inclusão é como a globalização, não tem volta, nosso lugar é na escola, espaço de pertencimento, de conquistas da cidadania, enfim, da construção de identidades.

No processo de inclusão escolar, um dos maiores desafios que estamos enfrentando é o recorrente discurso de que um dos entraves à inclusão são exatamente os problemas na formação inicial dos professores. Isso ficou demonstrado nos depoimentos durante as entrevistas. Partilha dessa premissa, Lopes e Valdés, (2003, p. 196), ao considerar que:

Quando se fala em processo de inclusão, já é um motivo que leva ao aprimoramento da formação profissional dos professores, constituindo um motivo para que a escola se modernize em prol de uma sociedade 
a qual não deverá haver espaços para preconceitos, discriminação, barreiras sociais e/ou culturais.

No sistema educacional, não se constitui uma tarefa fácil mudar a concepção de que realmente falta formação para o trabalho com pessoas com deficiência. A partir das reflexões durante a pesquisa, conseguimos identificar que o sistema não vê com bons olhos o discurso de que a falta de formação é um entrave ao processo de inclusão. Essa premissa não é bem aceita pelo sistema, uma vez que acredita oferecer formação suficiente para trabalhar com as demandas de alunos com deficiência, transtornos globais do desenvolvimento, altas habilidades/superdotação.

Assim, para o sistema, a falta de formação não é um entrave à inclusão desses novos sujeitos, presentes hoje no espaço escolar. Frente a essa assertiva, Martins (2006, p. 25), assinala que

É necessário, principalmente, investir tempo, esforços e recursos para que ela deixe de ser apenas um aspecto garantido na legislação e em documentos educacionais, uma utopia ou uma mera formalidade como ainda é considerado por muitos - para ser uma realidade nas escolas regulares brasileiras, de uma forma geral.

$\mathrm{Na}$ perspectiva de se efetivar uma escola inclusiva, visando maior possibilidade de escolarização dos alunos com deficiência, faz-se necessário que todos os segmentos da unidade de ensino estejam envolvidos. Frente ao exposto, consideramos ser da maior relevância o trabalho colaborativo, envolvendo todos os profissionais que compõem o quadro da escola.

No contexto da formação inicial dos professores, pensamos que, na escola, é possível verificar que o processo de inclusão teria maior flexibilidade se a educação do aluno com deficiência estivesse permeada por múltiplas ações pedagógicas diferenciadas, pois, a escolarização desse, necessariamente, requer uma escola estruturada, no sentido de atender às suas necessidades educativas especiais. Essa premissa é partilhada por Pires (2006), ao acentuar que quando os 
educadores estão verdadeiramente engajados no processo de inclusão, este se efetiva, uma vez que há por esses profissionais envolvimento nos processos inclusivos.

AGRADECIMENTOS: CAPES - Coordenação de Aperfeiçoamento de Pessoal de Nível Superior.

\section{Referências}

BRASIL. Lei n. 9.394, de 20 de dezembro de 1996. Lei de diretrizes e bases da educação nacional. Diário Oficial da União, Brasília, DF, 23 dez. 1996.

BRASIL. Conselho Nacional de Educação, 2006.

CHACON, Miguel Claudio Moriel. Formação de recursos humanos em educação especial: resposta das universidades à Portaria Ministerial n. 1793. Revista Brasileira de Educação Especial, Marília, v. 10, n. 3, p. 321-336, 2004.

COSTA, Vanderlei Balbino. Adaptação curricular: das dificuldades às possibilidades. Encontro de Pesquisa em Educação da região Centro Oeste reunião científica regional da ANPED: Projeto Nacional de Educação: desafios éticos, políticos e culturais, 13, 2016. Brasília. Anais. Brasília: Universidade de Brasília (UNB), ANPED, 2016.

SANTOS, Ana Lea Bispo. SANTOS FILHO, Arlindo Paulo dos. SANTOS, José Walter. ARAUJO, Maria José de Azevedo. A Educação Inclusiva e a relação com a formação de professores. 2006. Disponível em:

https://openrit.grupotiradentes.com/xmlui/bitstream/handle/set/2211/A\%20ED UCA $\%$ C3 $\% 87 \%$ C3\%83O $\% 20 I N C L U S I V A \% 20$ E $\% 20$ A $\% 20$ RELA $\%$ C3\%87\%C3\%8 3O $\% 20$ COM $\% 20$ A $\% 20$ FORMA $\%$ C3\%87\%C3\%83O $\% 20$ DE $\% 20$ PROFESSORES $\%$ 20\%28UNIT-SE\%29.pdf?sequence=1. Acesso em: 25 jun. 2019.

FERREIRA, Júlio Roméro. A nova LDB e as necessidades educativas especiais. Cad. CEDES, Campinas, v. 1, n. 46, set. 1998. 
FIORI, Ernane Maria. Conscientização e Educação. Educação \& Realidade, Porto Alegre, v. 11, n. 1, p. 3-10, 1986.

LAPLANE, Adriana. Uma análise das condições para a implementação das políticas de educação inclusiva no Brasil e na Inglaterra. Educ. Soc., Campinas, v. 27, n. 96 - Especial, p. 689-715, out. 2006.

LÜDKE, Menga; André, Marli E. D. A. Pesquisa em Educação: abordagens qualitativas. São Paulo: EPU, 1986.

MANTOAN, Maria Tereza Egler. Inclusão escolar: O que é? Por quê? Como fazer? São Paulo: Moderna, 2003.

MARTINS, Lúcia Araújo Ramos [org.]. Inclusão: compartilhando saberes. Petrópolis: Vozes, 2006.

MAZZOTTA, Marcos José Silveira. Educação especial no Brasil: história e políticas públicas. 5. ed. São Paulo: Cortez, 2005.

PIANA, Maria Cristina. A construção da pesquisa documental: avanços e desafios na atuação do serviço social. São Paulo: Cultura Acadêmica, 2009.

PIRES, José. A questão ética frente às diferenças: uma perspectiva da pessoa como valor. In: MARTINS, Lúcia Araújo Ramos et al (org.). Inclusão: compartilhando saberes. Petrópolis:

Ed. Vozes, 2006.

SEVERINO, Antônio Joaquim. Metodologia do trabalho científico. 23. ed. São Paulo: Cortez, 2007.

THOMA, Adriana Silva. A inclusão no ensino superior: discursos e representações sobre alunos com necessidades especiais nas IES comunitárias do Rio Grande do Sul In: REUNIÃO ANUAL SBPC, 58o, 2006. Florianópolis. Anais. Florianópolis, 2006. 
VALDÉS, Maria Teresa Moreno. Formação de professores de educação física que atuam com alunos com necessidades educacionais especiais (Deficiência Auditiva): uma experiência no ensino fundamental da rede pública de Fortaleza. Revista Brasileira de Educação Especial, Marília, v. 9, n. 2, p. 195210, 2003.

LOPES, Noêmia. 24 respostas sobre as principais dúvidas da inclusão, 2010. Disponível em: https: //gestaoescolar.org.br/conteudo/205/24-respostas-para-asprincipais-duvidas sobre inclusão. Acesso em: 28 fev. 2019. 